\title{
EL RÉGIMEN CONSTITUCIONAL DE LAS REMUNERACIONES DE LOS SERVIDORES PÚBLICOS DEL ESTADO MEXICANO ${ }^{1}$
}

A mi hermano Gustavo, por la obtención de su grado de doctor en ciencias

\section{INTROITO}

En la campaña electoral de 2006, en especial la dedicada a la renovación del Poder Ejecutivo federal, destacó la propuesta de crear topes constitucionales a las remuneraciones de los servidores públicos. Concluido el difícil proceso electoral, la propuesta fue retomada por la fracción de la izquierda en el Senado y por el Presidente de la República, a través de sendas iniciativas de reformas y adiciones a la Constitución, en especial a su artículo $127 .{ }^{2} \mathrm{El}$ procedimiento de revisión constitucional fue de interés nacional, como lo resaltaron los medios masivos de comunicación entre 2006 y 2009, ya que siempre se ventilaban los escandalosos pagos de remuneraciones excesivas para ciertos servidores públicos o el otorgamiento de "jubilaciones tempranas", sobre todo en las entidades paraestatales del sector financiero, los que sin duda han generado inconformidad en la sociedad mexicana. El procedimiento de la revisión constitucional también resultó complejo, pues fueron recuperadas las diversas iniciativas de reformas y adiciones a la ley fundamental en materia de remuneraciones.

1 Para la elaboración de este comentario conté con el apoyo del Dr. Gustavo Pérez López y de Ángel Alberto Pérez López.

2 Cuando a lo largo de este comentario se cite un artículo, se entenderá que pertenece a la Constitución Política de los Estados Unidos Mexicanos. 
El presente trabajo procurará exponer, de forma apretada, cómo se gestó la reforma constitucional en materia de remuneraciones de 2009 y tratará de analizar el contenido de los nuevos referentes del sistema de percepciones de los servidores públicos del Estado mexicano, tema tímidamente abordado por la doctrina constitucional, pero de alto interés social. $^{3}$

\section{EL PROCEDIMIENTO DE LA REFORMA}

\section{Las iniciativas ante el Senado de la República}

\section{A. La iniciativa de los partidos de la Revolución Democrática (PRD), del Trabajo y Convergencia}

La iniciativa, suscrita por 13 senadores y presentada por el senador Pablo Gómez, lamentaba la ausencia de una política ordenadora de las percepciones en los ámbitos del poder público (Federación, estados, Distrito Federal y municipios) y sus diversas formas de expresión (poderes y órganos). ${ }^{4}$ En el documento se resalta genéricamente que el sueldo de los servidores públicos es adicionado con otras percepciones, de forma discrecional y aparentemente sin apoyo en lo aprobado en los presupuestos respectivos. Por ello, los senadores autores de la adición de un segundo párrafo del artículo 127, consideraban que era indispensable la dignificación de la función pública, mediante el establecimiento de sueldos adecuados y transparentes, que no fuesen aumentados mediante argucias administrativas.

3 El contenido del artículo 127 ha sido tratado por Quintana Aceves, Federico, “Comentario al artículo 127”, Constitución Política de los Estados Unidos Mexicanos comentada, México, UNAM, 1985, pp. 318-319; Mijangos Borja, María de la Luz, “Comentario al artículo 127”, Derechos del pueblo mexicano. México a través de sus Constituciones, 4a. ed., México, Cámara de Diputados, LV Legislatura, 1994, t. XII, pp. 1019-1024; Nieto Castillo, Santiago, "Comentario al artículo 127", Constitución Política de los Estados Unidos Mexicanos comentada, 19a. ed., México, UNAM, 2006, t. V, p. 81, y Carbonell, Miguel, Constitución Política de los Estados Unidos Mexicanos comentada, México, Porrúa-UNAM-Comisión Nacional de los Derechos Humanos, 2007, pp. 787 y 788 .

4 Gaceta del Senado del 9 de noviembre de 2006. 
La adición constitucional se justificaba a fin de sentar la base común, suprema y obligatoria para todos los ámbitos del sistema federal, respecto de las remuneraciones de los servidores públicos. El segundo párrafo propuesto para el artículo 127 indicaba un sueldo máximo anual de treinta y tres mil veces el salario mínimo general diario vigente para el Distrito Federal, destinado a todos los servidores públicos del Estado mexicano, que debería incluir toda percepción, directa o indirecta, en efectivo o en especie, a que tendrían derecho dichos servidores, exponiéndose de forma sumamente extensa y puntillosa las percepciones. También se establecía que los servidores públicos, sin distinción, que tuviesen más de un empleo, pensión o jubilación (sic), estarían impedidos de recibir una remuneración total o mayor que la prevista en la iniciativa, planteándoles la alternativa de decidir a cuál percepción debería renunciar. Eran fijadas las prohibiciones de percepciones personales simuladas y de otorgar jubilaciones, pensiones o haberes de retiro por servicios prestados, sin tener apoyo en una ley o decreto del poder legislativo.

El tercer transitorio de la iniciativa proponía que las percepciones de los ministros de la Suprema Corte de Justicia de la Nación, los magistrados del Tribunal Electoral del Poder Judicial de la Federación, los magistrados de Circuito, los jueces de Distrito y los consejeros de la Judicatura Federal, permaneciesen incólumes, por respeto al mandato prohibitivo del artículo 94 de la Constitución de no disminuir dichas percepciones durante el tiempo de sus encargos. De igual forma, se planteó que las percepciones de los integrantes del Consejo General del Instituto Federal Electoral fuesen mantenidas en sus términos a la entrada en vigor de la reforma, debido a que la Constitución señala que éstas deben ser iguales a las de los ministros de la Suprema Corte. Sin embargo, se preveía que, a partir de la entrada en vigor del decreto, estos servidores públicos, adicionalmente al sueldo nominal señalado en los presupuestos vigentes, no podrían recibir bonos, ayudas, premios, recompensas, estímulos, gastos de representación, comisiones, compensaciones o cualquier otra remuneración en dinero o en especie.

La iniciativa fue enviada a las Comisiones Unidas de Puntos Constitucionales y de Estudios Legislativos, Segunda. 


\section{B. La iniciativa del Ejecutivo federal}

Posteriormente, el presidente de la República presentó su iniciativa sobre la misma temática, ante la Comisión Permanente, proponiendo la reforma de los artículos 73, fracción XI, y $127 .{ }^{5}$ En la parte considerativa del documento se reconocía la necesidad nacional de contar con servidores públicos competentes, profesionales y honestos, que perciban remuneraciones adecuadas y dignas, sin descuidar las posibilidades presupuestales del Estado y la realidad económica del país.

El objeto de la iniciativa consistía en ajustar el régimen constitucional que sustenta las remuneraciones de todos los servidores públicos del país, "a fin de crear un justo y verdadero equilibrio entre la realidad económica que viven los gobernados y el eficiente desempeño del cargo con la remuneración que reciben sus gobernantes." De forma sintética, el Ejecutivo federal consideraba que las remuneraciones deberían mantenerse ajenas a todo exceso, reconociendo disparidades entre ingresos exageradamente elevados y regiones del país con población en extrema miseria y carente de servicios públicos básicos, que provocan expresiones de irritación social.

La propuesta presidencial consistió en la reforma de la fracción XI del artículo 73, a fin de que el Congreso de la Unión tuviera la facultad de expedir una ley nacional que estableciese las bases para fijar las remuneraciones de los servidores públicos de todos los poderes y órganos del Estado mexicano, en los términos del artículo 127.6 En cuanto a este precepto, se sugería su reforma total. Además de conservarse, de forma condensada, la previsión fundamental de que los servidores públicos recibirán remuneraciones adecuadas e irrenunciables por el desempeño de su función, empleo, cargo o comisión, se proponía que el artículo 123

5 Gaceta del Senado del 25 de enero de 2007.

6 Es de notarse que en otra iniciativa del Presidente Felipe Calderón Hinojosa, también se propuso una facultad legislativa al Congreso de la Unión de alcance nacional, a fin de que expidiese leyes en materia de contabilidad gubernamental, que regirán la contabilidad pública y la presentación homogénea de información financiera, de ingresos y egresos, así como patrimonial, tanto para la Federación, los Estados, los Municipios, el Distrito Federal y sus órganos político-administrativos de sus demarcaciones territoriales (fracción XXVIII del artículo 73), misma que fue incorporada a la Constitución General de la República, mediante el decreto publicado en el Diario Oficial de la Federación del 7 de mayo de 2008 . 
se desenvolviese en ocho bases (en apartados) que regirían el sistema de las remuneraciones: a) definición constitucional de las remuneraciones, b) fijación de la remuneración del presidente de la República como tope salarial a nivel nacional, c) prohibición de que un servidor público percibiese una remuneración mayor a la concedida a su superior jerárquico inmediato, d) consagración de un conjunto de principios constitucionales aplicables a la fijación presupuestal de los montos mínimos y máximos de las remuneraciones, e) especificación en las remuneraciones de la totalidad de las contraprestaciones, f) publicidad de tabuladores y remuneraciones, g) proporcionalidad de las remuneraciones, y h) creación de órganos colegiados para la fijación de los tabuladores.

En cuanto a los transitorios del decreto de reforma constitucional propuesto por el Ejecutivo, se establecía que a) entraría en vigor al día siguiente de su publicación en el Diario Oficial de la Federación; b) las remuneraciones de los servidores públicos que, a la fecha de entrada en vigor del decreto rebasen aquéllas correspondientes al Ejecutivo de la Unión o las de su superior jerárquico, deberán ajustarse a lo dispuesto en el artículo 127, a más tardar al inicio del ejercicio fiscal 2008, en el entendido de que la reforma propuesta aparecería en ese año, y c) el Presidente de la República llevaría a cabo un estudio a nivel nacional de las remuneraciones de los servidores públicos, para contar con un marco de referencia y definir la metodología para la valuación de puestos y recomendaciones en cuanto a los esquemas de remuneraciones, para lo cual todos los órganos públicos, sin excepción, le harían llegar la información que el Ejecutivo le requiriese.

En el caso de esta iniciativa, fue remitida a la Comisión de Puntos Constitucionales del Senado. ${ }^{7}$

\section{El primer dictamen de la Cámara de Senadores}

Las Comisiones Unidas de Puntos Constitucionales y de Estudios Legislativos, Segunda, emitieron el dictamen correspondiente a las iniciativas de modificación constitucional dedicadas a las remuneraciones de los

7 Por acuerdo de la Junta de Coordinación Política de la Cámara de Senadores, aprobado por el pleno de ésta el 27 de febrero de 2007, se modificó el turnó y se decidió también remitir la iniciativa presidencial a la Comisión de Estudios Legislativos, Segunda. 
servidores públicos. ${ }^{8}$ Después de relacionar las dos iniciativas y resumir el contenido de las mismas, las dictaminadoras consideraron viables las propuestas, en especial la necesidad de reformar el artículo 127, mas estimaron que deberían introducirse modificaciones sustanciales de forma puntual: a) por respeto a la autonomía de los Estados y del Distrito Federal, se determinó improcedente la reforma de la fracción XI del artículo 73 ; b) cambiar el acápite del artículo 127, en lo tocante a la enumeración un poco más precisa de los ámbitos del sistema federal mexicano, poderes, órganos y entes públicos, así como agregar la proporcionalidad de las remuneraciones con respecto a las responsabilidades de los empleos públicos; c) equiparar las figuras de remuneración y retribución, además de ampliar los conceptos que las abarcan; d) si bien se reconocieron a las pensiones y jubilaciones como derechos sociales de los trabajadores, y no ser parte de la remuneración de un servidor público, las comisiones examinaron la problemática de las "jubilaciones tempranas", fuente de inconformidad pública, y sugirieron la proscripción constitucional de jubilaciones, pensiones, haberes de retiro y liquidaciones por servicios prestados que no estuviesen asignadas por la ley, decreto legislativo, contrato colectivo o condiciones generales de trabajo; e) advertir que tener como referente de tope salarial máximo a la remuneración del Titular del Ejecutivo de la Unión, de ninguna manera debe ser interpretado como una preeminencia constitucional de dicho poder federal sobre los otros; f) reconocer la legitimidad de que, en algunos casos, existen servidores públicos que pueden desempeñar varios empleos, por lo que se consideró preciso aclarar que el excedente de sus remuneraciones debería ser a consecuencia del desempeño de varios cargos públicos y la suma de dichas retribuciones no podría exceder la mitad de la remuneración establecida para el Presidente de la República en el presupuesto correspondiente; g) retirar la referencia a "contraprestaciones", para mejor emplear los términos "elementos fijos y variables", conforme a lo dispuesto en las materias laboral y de la seguridad social; h) proponer una facultad coincidente para el Congreso de la Unión, las legislaturas locales y la Asamblea Legislativa del Distrito Federal para expedir leyes reglamentarias, en sus respectivos ámbitos, del artículo 127, así como para que las mismas estableciesen sanciones penales y administrativas de las conductas que impliquen el incumplimiento o la elusión por simulación de lo establecido

8 Gaceta del Senado del 12 de marzo de 2007. 
en dicho precepto constitucional; i) crear una indefectible concordancia entre el nuevo artículo 127 con los artículos 75 (señalamiento de remuneraciones en el Presupuesto de Egresos de la Federación), 115, fracción IV (mandato a los presupuestos municipales de señalar remuneraciones de los servidores públicos) y 123, apartado B, fracción IV (salarios de los trabajadores al servicio del Estado); j) cambio de técnica legislativa al artículo 127 (de apartados a fracciones de numeral romano), k) la declaración de preminencia del artículo 127 sobre cualquier otra disposición que establezca y regule remuneraciones a servidores públicos, sea en la Constitución o en cualquier otro ordenamiento (último párrafo del numeral citado), y 1) ampliación del régimen transitorio del decreto de reformas a la Constitución.

\section{La discusión en el Senado}

El dictamen con proyecto de decreto que reformaba los artículos 75 , 115,123 y 127, fue discutido en la sesión plenaria del 12 de marzo de 2007, donde hicieron uso de la palabra los senadores Pedro Joaquín Coldwell, Pablo Gómez Álvarez y José González Morfín, a favor del dictamen. El proyecto de decreto fue aprobado por 105 votos, sin voto alguno en contra, pasando a la colegisladora.

\section{El dictamen de la Cámara de Diputados}

La minuta del Senado fue presentada ante el pleno de la Representación Nacional en su sesión del 15 de marzo de 2007, turnándose a las Comisiones Unidas de Puntos Constitucionales y de la Función Pública, las que formularon su dictamen en marzo de $2009 .{ }^{9}$

Antes de entrar al contenido de la minuta senatorial, las comisiones dictaminadoras relacionaron como antecedentes a un conjunto de catorce iniciativas de reforma constitucional suscritas por diputados federales, en lo individual o en nombre de los grupos parlamentarios, o provenientes de las legislaturas locales, presentadas entre 2002 y 2008, que coincidían con la materia del documento enviado por el Senado: la regulación de las remuneraciones de los servidores públicos. Esta es una muestra de la

9 Gaceta Parlamentaria de la Cámara de Diputados del 26 de marzo de 2009. 
gran preocupación por tratar de establecer nuevos referentes en la Ley Fundamental para fijar límites objetivos y permanentes a las percepciones de los servidores públicos del Estado mexicano, a fin de superar la fijación salarial arbitraria y excesiva.

Las comisiones expresaron su concurrencia con la voluntad de la colegisladora de fijar un marco constitucional para las remuneraciones de los servidores públicos, sin desconocer las iniciativas allegadas a la Cámara de Diputados, por lo que, en aras de enriquecer y fortalecer lo aprobado por el Senado, se propusieron modificaciones a lo aprobado por la colegisladora. El dictamen abundó sobre la desproporción entre los salarios de los altos funcionarios del Estado mexicano y la situación de la economía nacional, sin omitir la reprobación del cuerpo social a las tendencias de asignar remuneraciones conforme a la apreciación personal del servidor público y de establecer en instrumentos laborales liquidaciones ominosas para ciertos servidores públicos.

Las modificaciones a la minuta fueron las siguientes: a) la inclusión de los tabuladores desglosados de las remuneraciones que se propone perciban sus servidores públicos para la Federación, los Estados, los municipios y el Distrito Federal, en sus respectivos presupuestos de egresos, lo que implicaría, para dicho orden de entidades, la adición de dos párrafos al artículo 75, la reforma del párrafo cuarto de la fracción IV del artículo 115, la adición de dos párrafos a la fracción I del artículos 116 y el agregado de un segundo párrafo al inciso b) de la fracción $\mathrm{V}$, apartado $\mathrm{C}$, del artículo 122; b) una reordenación de los términos de la fracción IV del apartado B del artículo 123; c) exclusión de la fracción I del artículo 127 , de las aportaciones a fondos de retiro o de ahorro como parte de las remuneraciones; d) modificación de la fracción II del artículo 127 para vincularla con la fracción I del mismo numeral; e) cambio a la fracción III del artículo 127, para agregar la permisión de que un servidor público supere la remuneración de su superior jerárquico cuando su percepción sea producto de las condiciones generales de trabajo derivado de un trabajo técnico calificado o por especialización en su función; f) adición a la fracción IV del 127, para que la referencia de préstamos y créditos en el conjunto de percepciones extraordinarias que deben estar señaladas en la ley, decreto legislativo, contrato colectivo o condiciones generales de trabajo, así como la aclaración de que dichos conceptos no formarán parte de la remuneración y que los servicios de seguridad social quedasen excluidos de aquélla, cuando los servidores públicos por razón del car- 
go desempeñado así lo requieran; g) eliminación del último párrafo del artículo 127, que establecía la preeminencia de este precepto sobre otras prescripciones de la misma Constitución y de otros ordenamientos, y h) modificaciones al transitorio tercero del decreto.

El 31 de marzo de 2009 el proyecto de decreto fue aprobado en la Cámara de Diputados con 365 votos en pro, uno en contra y dos abstenciones, y por los cambios introducidos fue devuelto a la Cámara de Senadores para los efectos de lo dispuesto en el apartado E del artículo 72.

\section{El segundo dictamen del Senado}

El 2 de abril de 2009, la minuta proveniente de la colegisladora fue turnada a las Comisiones Unidas de Puntos Constitucionales y de Estudios Legislativos, Segunda, las que emitieron dictamen el 21 de abril de 2009. ${ }^{10}$ En el dictamen, después de resumir el contenido de la minuta y destacar los cambios aprobados por la Cámara de Diputados, se concluye que las modificaciones introducidas son procedentes y viables en sus términos. En todo caso, se propuso una adecuación menor de orden gramatical en el párrafo segundo, del inciso b) de la fracción $\mathrm{V}$ de la Base Primera, del apartado C del artículo 122.

El 28 de abril de 2009, después de las intervenciones de los senadores Pablo Gómez, Francisco Arroyo Vieyra, Santiago Creel y Ricardo García Cervantes, apuntalando el contenido de la reforma constitucional, el proyecto de decreto que reforma y adiciona los artículos 75, 115, 116, 122, 123 y 127, fue aprobado en la Cámara de Senadores con 82 votos en pro, remitiéndose a las legislaturas locales para los efectos del artículo 135.

\section{Cómputo de los votos de las legislaturas locales y declaratoria de aprobación de las reformas y adiciones}

La Comisión Permanente, en su sesión del 22 de julio de 2009, 1levó a cabo el cómputo de 17 votos aprobatorios del proyecto de Decreto en la materia de remuneraciones de los servidores públicos, por lo que formuló la declaratoria de aprobación del decreto de reformas y adiciones a los artículos 75, 115, 116, 122, 123 y 127. En consecuencia, se ordenó enviar 
el decreto al presidente de la República para su promulgación, siendo publicado en el Diario Oficial de la Federación del 24 de agosto de 2009, entrando en vigor al día siguiente de su publicación (transitorio primero del decreto). ${ }^{11}$

\section{EL NUEVO SISTEMA CONSTITUCIONAL}

DE LAS REMUNERACIONES DE LOS SERVIDORES PÚBLICOS

El sistema instituido por la reforma de agosto de 2009 tiene como eje rector el nuevo contenido del artículo 127, con el que se vinculan indefectiblemente los otros preceptos reformados y adicionados en el mismo decreto, a fin de que en todos los ámbitos del régimen federal mexicano se trate de ver cumplido el contenido prescriptivo del 127, además de vincular esta disposición con la fijación salarial del apartado B del artículo 123. En atención a ello, primero se tratará de exponer el contenido del artículo 127, para después presentar cómo se da una vinculación sistemática de dicho precepto rector con dispositivos constitucionales que permitirán su aplicación puntual en los ámbitos federal, estatales, local del Distrito Federal y municipal, y al final tratar la relación del artículo 127 con la materia burocrática.

\section{El nuevo artículo 127}

\section{A. Ámbito personal de aplicación y el derecho a la remuneración}

De ser un artículo de naturaleza declarativa y redacción escasa así como deficiente (que rayaba lo casuístico), el nuevo precepto crece tanto de forma como de sustancia.

En lo formal, aumenta considerablemente en dos párrafos, siendo el segundo subdividido en seis fracciones. En cuanto a lo sustancial, el artículo 127 se adapta a la nueva relación de entes públicos integrantes del Estado mexicano, abandonando los contenidos puntuales de las dos

11 Además, el primer transitorio del decreto establece, de forma excesivamente genérica e imprecisa, que las disposiciones que contravengan el contenido del Decreto quedarán sin efecto. 
reformas que tuvo esa disposición, y detalla el régimen de las remuneraciones de los servidores públicos, mediante las bases que incorpora.

En el primer párrafo se establece un dilatado ámbito personal de aplicación: el universo de servidores públicos de la Federación, de los Estados, del Distrito Federal y de los municipios, de sus entidades y dependencias (siendo tal vez reiterativo al mencionar a "sus administraciones paraestatales y paramunicipales, fideicomisos públicos", las que se integran por entidades), de instituciones y órganos autónomos, y de cualquier ente público.

En el mismo primer párrafo, se prescribe que los servidores públicos del Estado mexicano recibirán una remuneración adecuada e irrenunciable por el desempeño de su función, empleo, cargo o comisión, agregándose que será proporcional al grado de sus responsabilidades. ${ }^{12}$ Sin duda, es un derecho de la función pública. ${ }^{13}$

El segundo párrafo prevé que las remuneraciones serán determinadas de forma anual y equitativa en los presupuestos de egresos correspondientes, lo que viene a ser un mandato para quienes deben preparar los proyectos de dichos presupuestos como para los órganos encargados de su aprobación. La determinación de las remuneraciones queda sujeta a las bases que despliega el artículo 127 en el siguiente orden.

\section{B. Definición jurídica de las remuneraciones y percepciones excluidas de dicha definición}

La fracción I del artículo 127 fija una definición de remuneración (a la que también denomina retribución), considerándola como "toda percepción en efectivo o en especie, incluyendo dietas, aguinaldos, gratificaciones, premios, recompensas, bonos, estímulos, comisiones, compensaciones y cualquier otra, con excepción de los apoyos y los gastos sujetos a comprobación que sean propios del desarrollo del trabajo y los gastos de

12 Cfr. Mijangos Borja, María de la Luz, op. cit., nota 2, pp. 1022 y 1023.

13 Debe dejarse nota que en cierto momento de la historia política reciente se dio el caso de un servidor público, al que se eximió, por decirlo de alguna forma, de obtener una remuneración por el desempeño de la comisión que le fue encomendada. Fue el caso de Manuel Camacho Solís, cuando fue designado como Comisionado para la Paz en el estado de Chiapas en enero de 1994, por el entonces presidente Carlos Salinas de Gortari. 
viaje en actividades oficiales." Se puede apreciar la amplitud de la definición constitucional.

La fracción IV excluye del concepto de remuneraciones a las siguientes prestaciones, siempre y cuando sean otorgados por ley, decreto legislativo, contrato colectivo o condiciones generales de trabajo: las jubilaciones, pensiones o haberes de retiro, las liquidaciones por servicios prestados, los préstamos y los créditos.

\section{El tope máximo de las remuneraciones}

La fracción II consagra el leitmotiv del sustancioso conjunto de las iniciativas que antecedieron a la reforma de agosto de 2009: la prohibición que ningún servidor público recibiese una remuneración mayor a la establecida para el Presidente de la República en el presupuesto correspondiente. Se entiende que la prohibición abarca a todos los ámbitos del poder público en el Estado mexicano: federal, estatal, local del Distrito Federal (incluyendo a sus demarcaciones territoriales) y municipales.

A efecto de ajustar todas las remuneraciones del Estado mexicano, la reforma contiene los transitorios segundo y tercero. En el segundo transitorio, se dispuso que las remuneraciones vigentes en el ejercicio fiscal de 2009 y que sean superiores a la máxima establecida en la fracción II del artículo 127, deberán ajustarse, e inclusive serán disminuidas, en los presupuestos de egresos para el ejercicio fiscal de 2010.

El transitorio tercero, al mismo tiempo, procura salvaguardar una garantía institucional esencial para el buen funcionamiento del Poder Judicial: la prohibición de disminuir las remuneraciones de los juzgadores durante su encargo, así como mantener la equivalencia de las remuneraciones de los miembros del Consejo General del Instituto Federal Electoral con la de los Ministros de la Suprema Corte de Justicia de la Nación, a fin de contemporizar lo previsto en los artículos 17, 94, 116, fracción III, y 41, fracción $\mathrm{V}$, con el tope máximo de las remuneraciones de la fracción II del artículo 127. A tal efecto, el tercer transitorio prevé que las retribuciones nominales de los ministros de la Suprema Corte de Justicia de la Nación, los magistrados del Tribunal Electoral del Poder Judicial de la Federación, los magistrados de Circuito, los jueces de Distrito, los consejeros de la Judicatura Federal, los magistrados y jueces de los Poderes Judiciales Estatales y los integrantes del Consejo General del Insti- 
tuto Federal Electoral, en funciones al momento de entrar en vigor la reforma constitucional de agosto de 2009, se mantendrán durante el tiempo que dure su encargo, a fin de salvaguardar su independencia y estabilidad en el ejercicio de sus cargos. También se prevé que las remuneraciones adicionales a las nominales (gratificaciones, premios, recompensas, bonos, estímulos, comisiones, compensaciones, y cualquier remuneración en dinero o especie) se mantendrán en tanto que la remuneración total no exceda el máximo establecido en la fracción II del artículo 127, así como que los incrementos a las retribuciones nominales o adicionales sólo podrán realizarse si la remuneración total no excede el monto máximo.

\section{Limites constitucionales a las remuneraciones}

En referencia a las remuneraciones de los titulares de entidades paraestatales de la administración pública federal paraestatal comparadas con la correspondiente al titular del Ejecutivo de la Unión, el numeral III del artículo 127 impone la prohibición de que ningún servidor público obtendrá una remuneración igual o mayor que la percibida por su superior jerárquico, con la salvedad de los casos en que el excedente sea consecuencia del desempeño de varios empleos públicos (como se da con regularidad en el caso del personal docente, que se ve obligado a trabajar varios turnos, en una jornada de trabajo), que la remuneración sea producto de las condiciones generales de trabajo, derivado de un trabajo técnico calificado o por especialización en su función. Asimismo, se dispone que la suma de esas retribuciones no deberá exceder la mitad de la remuneración que el presupuesto atribuya al presidente de la República.

Como ya antes se expuso, en la fracción IV del artículo 127 se prescribe que las jubilaciones, pensiones o haberes de retiro, liquidaciones por servicios prestados así como los préstamos o créditos, únicamente serán concedidas cuando estén asignadas por ley, decreto legislativo, contrato colectivo o condiciones generales de trabajo, siendo excluidos los servicios de seguridad social que requieran los servidores públicos, en razón de su cargo. 


\section{E. Publicidad de las remuneraciones}

Sin duda estamos ante un reflejo de la política de Estado de transparentar el ejercicio de la función pública, en especial permitir el ejercicio del derecho de acceso a la información contenido en el artículo 6, en los términos en que fue incorporado, mediante la reforma constitucional publicada el 20 de julio de 2007.

La fracción $\mathrm{V}$ del artículo 127 obliga a la publicidad de las remuneraciones y sus tabuladores, los que deberán señalar puntualmente la totalidad de sus elementos fijos y variables, tanto en efectivo como en especie. Estamos ante una concordancia de los contenidos de los artículos 6o. y 127 , en beneficio de la transparencia.

\section{F. Facultad coincidente en materia de remuneraciones de servidores públicos}

La fracción VI del nuevo artículo 127 determina una facultad coincidente para los poderes legislativos federal y de los Estados, así como para la Asamblea Legislativa del Distrito Federal, a fin de que, en sus respectivos ámbitos competenciales, expidan las leyes reglamentarias dicho precepto fundamental y de las otras disposiciones constitucionales modificadas en esta reforma. Se hace una reserva específica respecto a las sanciones penales y administrativas que repriman las conductas que incumplan o eludan los nuevos imperativos constitucionales en materia de remuneraciones de los servidores públicos.

La facultad coincidente se ve ampliamente desarrollada en las modificaciones introducidas a los artículos 75, 115, 116 y 122, mediante el decreto de reformas de agosto de 2009, mismas que se comentarán en el siguiente apartado.

A fin de dar cumplimiento al mandato constitucional, el órgano revisor le impuso, por igual, al Congreso de la Unión, a las legislaturas locales y a la Asamblea Legislativa, un plazo de 180 días naturales contados a partir del día siguiente a su entrada en vigor (25 de agosto de 2009), mismo que se cumple el 20 de febrero de 2010, a fin de expedir o adecuar la legislación en materia de remuneraciones, así como para crear los tipos penales y las sanciones administrativas que correspondan para reprimir el incumplimiento o la elusión de la reforma constitucional de agosto de 
2009. El plazo en cuestión fue instituido en los transitorios cuarto y quinto del decreto de reformas y adiciones constitucionales que nos ocupa.

Es de resaltarse que esta reforma a la Ley Fundamental amplía, así sea de forma tímida, la competencia del órgano legislativo local del Distrito Federal en materia de responsabilidades administrativas, puesto que en dicha materia, la Asamblea sólo puede legislar en el caso de los servidores públicos del Tribunal Superior de Justicia de la Capital de la República (artículo 122, apartado C, Base Primera, fracción V, inciso m), por lo que, en atención al especial y alambicado sistema de distribución de potestades legislativas en el Distrito Federal, la materia de responsabilidades administrativas de los demás servidores públicos de la Capital, esencialmente corresponde al Congreso de la Unión, en su calidad de poder legislativo del Distrito Federal, de carácter residual. ${ }^{14}$

Además debe observarse que las legislaturas de los Estados emitirán los correspondientes ordenamientos legales en materia de remuneraciones aplicables tanto a los servidores públicos locales como a los municipales.

\section{Reformas a los artículos 75, 115, 116 y 122}

Como ya quedó expresado previamente, el nuevo artículo 127 surge como un precepto toral y referencial en materia de remuneraciones de los servidores públicos, donde está asentada una facultad coincidente que involucra a la Federación, los Estados y el Distrito Federal, a efecto de que emitan las correspondientes leyes reglamentarias de las disposiciones incorporadas a la Constitución General de la República. Consecuentemente, en la reforma de agosto de 2009 se incluyeron mandatos precisos que deben atender los entes legislativos tanto al expedir los ordenamientos dedicados a desarrollar en detalle el artículo 127, como también se

14 Sobre el esquema constitucional de la distribución de la potestad legislativa en el Distrito Federal, $c f r$. Pérez López, Miguel, "Estudio sobre el artículo 122 constitucional", Alegatos, México, núm. 38, enero-abril de 1998, pp. 33-46; id., "El derecho local del Distrito Federal en el nuevo artículo 122 constitucional", Revista del Instituto de la Judicatura Federal, México, núm. 2, junio de 1998, pp. 251-269, e id., "La distribución de la potestad legislativa local en el Distrito Federal", Cuestiones Constitucionales. Revista Mexicana de Derecho Constitucional, México, núm. 4, enero-junio de 2001, pp. 227237. 
añaden imperativos a los poderes y órganos encargados de formular los proyectos de presupuestos de egresos, de agregar tabuladores desglosados de las remuneraciones que deberían percibir sus servidores públicos. Veamos como se incorporan las modificaciones para los ámbitos federal, estatal, municipal y local del Distrito Federal, en lo particular y conforme a ese orden.

\section{A. Artículo 75}

A este precepto, cuyo objeto ha sido establecer una garantía de la función pública relativa a la continuidad presupuestal de las remuneraciones de los servidores públicos, lo que es definido por Miguel Carbonell como una especie de "reconducción presupuestal", ${ }^{15}$ le fueron adicionados dos párrafos. El nuevo párrafo segundo se vincula con el texto del acápite: el señalamiento de las retribuciones contenidas en el Presupuesto de Egresos de la Federación deberá respetar las bases del artículo 127 y sujetarse a las leyes que en la materia expida el Congreso de la Unión.

En cuanto al tercer párrafo, presenta un deber común para todos los poderes y órganos: la inclusión de los tabuladores desglosados de las remuneraciones de los servidores públicos en los proyectos de los presupuestos. En el caso particular del tercer párrafo, se especifica que los poderes legislativo, ejecutivo y judicial de la Federación, así como los organismos constitucionales autónomos que ejerzan recursos del Presupuesto de Egresos, deberán incluir los tabuladores desglosados de las remuneraciones que se propone perciban sus servidores públicos, dentro de sus proyectos de presupuestos. Las propuestas observarán el procedimiento señalado en la fracción IV del artículo 74 para la aprobación del presupuesto de egresos, así como las demás disposiciones legales aplicables.

B. Artículo 116

En cuanto al ámbito de la estructura constitucional de los Estados de la Unión, fueron adicionados los párrafos cuarto y quinto a la fracción II

15 Carbonell, Miguel, op. cit., nota 2, p. 484. 
del artículo 116, dedicado al poder legislativo local, recorriéndose en su orden los actuales cuarto y quinto.

El nuevo cuarto párrafo explicita una previsión ya existente en las Constituciones de los Estados: que las legislaturas locales tienen a su cargo la aprobación del presupuesto de egresos. Esta disposición deberá vincularse con el artículo 127, cuando los poderes legislativos señalen las remuneraciones de los servidores públicos, y de forma similar al tercer párrafo del numeral 75 , se ordena a los poderes locales y a los órganos constitucionales autónomos de los Estados que incluyan los tabuladores desglosados de las remuneraciones de sus servidores públicos en los proyectos de presupuestos a su cargo y que sus propuestas deberán observar el procedimiento para la aprobación de los presupuestos de egresos, conforme a lo establecido en las Constituciones y leyes locales.

\section{Artículo 115}

En cuanto al régimen constitucional municipal, fue reformado el párrafo cuarto del inciso c) de la fracción IV del artículo 115, a fin de agregar a la atribución de los ayuntamientos de aprobar sus presupuestos de egresos, que en éstos deberán incluirse los tabuladores desglosados de las remuneraciones de los servidores públicos municipales, sujetándose a las disposiciones del artículo 127.

\section{Artículo 122}

Para el caso del Distrito Federal, el decreto de agosto de 2009 estableció la reforma del primer párrafo del inciso b) de la fracción $\mathrm{V}$ de la Base Primera del apartado $\mathrm{C}$ del artículo 122 y la adición de un párrafo segundo en dicho inciso b), recorriéndose en su orden los que eran los párrafos segundo a quinto. En su conjunto, se ordena, en primer lugar, a la Asamblea Legislativa que, al señalar las remuneraciones de los servidores públicos del Distrito Federal, deberá sujetarse a las bases contenidas en el artículo 127, y, en segundo término, a los órganos locales de gobierno y a los organismos con autonomía reconocida en el Estatuto de Gobierno del Distrito Federal a que incluyan en sus proyectos de presupuestos, los tabuladores desglosados de las remuneraciones de sus servidores públicos. 
Las propuestas de remuneraciones y tabuladores deberán observar el procedimiento para la aprobación del presupuesto de egresos del Distrito Federal, conforme las normas previstas en el Estatuto de Gobierno y en las leyes aplicables.

De estas reformas y adiciones al artículo 122 resalta la mención expresa, por vez primera, de los organismos con autonomía reconocida en el Estatuto de Gobierno del Distrito Federal, lo que abre la posibilidad de instituir dichas figuras para el ámbito local. En el Estatuto de Gobierno se reconocen de forma explícita como órganos dotados de autonomía del Distrito Federal al Tribunal de lo Contencioso Administrativo, ${ }^{16}$ el Instituto Electora $1{ }^{17}$ y el Tribunal Electoral. ${ }^{18}$

Aun cuando el Estatuto de Gobierno sea omiso, sin duda la Comisión de Derechos Humanos del Distrito Federal debe ser considerada como un órgano autónomo, conforme lo establecido en el apartado B del artículo $102 .{ }^{19}$

Además, deberá llevarse a cabo la ahora impostergable reforma del Estatuto de Gobierno, por parte del Congreso de la Unión, a efecto de reconocer el carácter de órgano público autónomo al Instituto de Acceso a la Información Pública del Distrito Federal, que la Ley de Transparencia y Acceso a la Información Pública del Distrito Federal le atribuye. ${ }^{20}$

\section{La modificación del artículo 123}

El órgano revisor de la Constitución reformó el primer párrafo de la fracción IV del apartado B del artículo 123, que prevé el derecho social de los trabajadores al servicio de los poderes de la Unión y del gobierno del Distrito Federal, de que sus salarios serán fijados en los presupuestos respectivos, sin que su cuantía pueda ser disminuida durante la vigencia de éstos, incorporando, mediante la reforma de agosto de 2009, que

16 Artículo 9 del Estatuto de Gobierno del Distrito Federal.

17 Artículo 123 del Estatuto de Gobierno del Distrito Federal.

18 Artículo 128 del Estatuto de Gobierno del Distrito Federal.

19 En el artículo 2o. de la Ley de la Comisión de Derechos Humanos del Distrito Federal (Gaceta Oficial del Distrito Federal de 22 de junio de 1993) se expresa que la Comisión es un órgano público autónomo.

20 Artículo 63 de la Ley de Transparencia y Acceso a la Información Pública del Distrito Federal (Gaceta Oficial del Distrito Federal del 28 de marzo de 2008). 
la fijación salarial deberá atender lo dispuesto en el artículo 127 y en la ley reglamentaria respectiva, que, para este caso, serían dos: una para el ámbito federal y otra para el Distrito Federal. Para este último supuesto, y como ya fue analizado, la Asamblea Legislativa tiene competencia expresa para legislar sobre este particular, de acuerdo con lo que se prevé en la fracción VI del artículo 127.

No debe ignorarse que las disposiciones del apartado B del artículo 123 se ven reflejadas en los ámbitos de los Estados y de los municipios, conforme lo disponen los artículos 116, fracción VI, y 115, fracción VIII, por lo que la reforma introducida a la fracción IV del apartado B también repercute en los regímenes burocráticos de esos ámbitos.

\section{COMENTARIOS FINALES}

Las reformas y adiciones a la Constitución General de la República creadoras de un nuevo y amplio régimen al que deberán sujetarse las remuneraciones de los servidores públicos del Estado mexicano, llegan en un momento difícil de la economía, tanto del país como del mundo. Es más, el recién incorporado encuadramiento constitucional de las remuneraciones de los servidores públicos surge en una coyuntura de tipo restrictivo para la función pública: la propuesta del Ejecutivo federal de desaparecer tres secretarías de Estado y su decisión de extinguir un organismo descentralizado: Luz y Fuerza del Centro.

Es de desearse que los poderes públicos y órganos estatales investidos de facultades y deberes por esta reforma, además de cumplir con el plazo constitucional de forma puntual, eviten afectaciones a la independencia de los poderes y entes públicos pretendiendo disminuir arbitrariamente sus remuneraciones, así como soslayar tentaciones demagógicas de fijar dichos emolumentos en cantidades ínfimas, a efecto de ostentar una supuesta honestidad que puede demeritar la eficiencia en el desempeño de la función pública.

Tampoco deben olvidarse a los sujetos sombreados de la reforma: los entes públicos encargados de la fiscalización, fortalecidos mediante la reforma constitucional de 2008, ${ }^{21}$ quienes están obligados a velar por el cumplimiento exacto de la nueva cauda de modificaciones al código po- 
lítico, a fin de denunciar simulaciones administrativas y presupuestales en la formulación de las remuneraciones, prevaricaciones legislativas, abandono de los nuevos principios constitucionales, afectaciones embozadas a la independencia otorgada a los poderes y órganos del Estado mexicano, y connivencias políticas que pretendan volver letra muerta los preceptos constitucionales que se ha tratado de comentar.

La sociedad, abatida tanto por la crisis económica como por los remedios aprobados desde el poder público para enfrentarla, reclama un ajuste a las remuneraciones de los altos servidores públicos del Estado mexicano, mientras en el inicio del siglo XXI continúa resonando el llamado del Patricio de Guelatao a los funcionarios públicos de "vivir, en la honrada medianía que proporciona la retribución que la ley les señala". 